\title{
The Efficacy of Na-Butyrate Encapsulated in Palm Fat on Experimentally Induced Necrotic Enteritis and Enumeration of intestinal resident Clostridium perfringens in Broiler Chickens
}

\author{
Awaad M. H. H. ${ }^{1}$, A. Atta ${ }^{2}$, Basma Shalaby ${ }^{3}$, H. B. Gharieb ${ }^{2}$, M. Elmenawey ${ }^{2}$, \\ K. Madian ${ }^{1}$, Eman, F. Farag ${ }^{3}$ and Amal, N. Awad ${ }^{3}$ \\ ${ }^{I}$ Faculty of Veterinary Medicine, Cairo University, Egypt \\ ${ }^{2}$ Faculty of Agriculture, Cairo University, Egypt \\ ${ }^{3}$ Animal Health Research Institute, Doki, Egypt.
}

\begin{abstract}
Experimental induction of necrotic enteritis (NE) successfully achieved by daily oral inoculation of $4 \times 10^{8}$ CFU of C. perfringens/bird in PBS for 4 successive days to immunocompromised broiler chickens (using $I B D V$ vaccination with a hot vaccine strain).

$N E$ infected bird groups showed variable degrees of diarrhea, inappetance enteritis and mortalities. Average lesion scoring indicated the efficacy of Na butyrate encapsulated in palm fat (Admix 30) in lowering damage associated with NE. The recorded mortality was lower in Admix 30 treated groups vs. their non-treated ones. Enumeration of intestinal C. perfringens in non-infected chickens (resident C. perfringens) as well as in experimentally induced $N E$ groups revealed reduction in the mean values in Admix 30 treated groups vs. nontreated infected ones. In conclusion; the present investigation proved the effectiveness of Admix 30 as a powerful environmentally friendly alternative for natural control method of NE in poultry enterprises.
\end{abstract}

Key words: Necrotic enteritis, Clostridium perfringens, acidifiers.

\section{Introduction}

C. perfringens is a spore-forming gram positive anaerobic rod which is a common inhabitant of the intestine of healthy broiler chickens belonging to the resident microbiota (Sengupta et al.; 2011) However, this microorganism along with predisposing factors causing mucosal damage (dietary ingredients or changes, severe stress, coccidiosis, or immunosuppressive affections) can collaborate to the overgrowth of $C$. perfringens and subsequent toxin production which is requisite to develop NE, (Barnes, 1997, Collier et al.;2008 and Llanco et al.; 2012). NE is an important clinical disease produced by $C$. perfringens that affects the poultry industry worldwide causing serious economic loss, about of two dollar billions/year (Kaldhusdal and Lovland; 2000). The intestinal number of $C$. perfringens in healthy and in NE-affected birds are different. The $C$. perfringens population is found to be normally less than $10^{2}$ to $10^{4}$ colony-forming units (CFU) per $\mathrm{g}$ of the intestinal contents in the small intestine of healthy chickens compared to $10^{7}-10^{9} \mathrm{CFU} / \mathrm{g}$ in diseased birds (Kondo, 1988). NE occurs in broilers aging between 2-6 weeks (Songer, 1996 and Cooper and Songer, 2010). In Europe the incidence of $C$. perfringens causing necrotic enteritis (NE) has increased since the ban on in-feed antibiotic growth promoters (AGP) (Van der Sluis, 2000 and Van Immerseel et al., 2004). Many recent studies of NE have focused on finding different ways to control this disease (Shojadoost et al., 2012). The issue of controlling $\mathrm{NE}$ and other enteropathogens without the use of AGP is becoming a big challenge. Accordingly; natural alternatives concepts based on natural ingredients for gastrointestinal tract (GIT) integrity and antibacterial action became highly commendable. Lückstädt (2003) mentioned under this point of view that acidifiers can be part of the feeding concept to replace AGP. Because of their pH-reducing and antimicrobial effects; acidifiers appear as one of the most feasible and functional alternative to AGP. Accordingly, experts in the poultry industry have given the use of acidifiers closer scrutiny. The auspicious effect of acidifiers over the organism is due to the better adhesion of the lactic acid bacteria to GIT epithelium in comparison with the pathogenic bacteria, and stooping the implementation of those bacteria over the mucus membranes of the intestine. Awaad et al (2011) has shown the interest of using protected organic acidifiers into the feed of broiler chickens submitted to $C$. perfringens infection and concluded that taking in consideration the facts that organic acids do not require withdrawal period, increase shelf-life of poultry products they can make a valuable contribution to flock health and safety of food that might provide a significant tool for the poultry industry in combating occurrence of intestinal diseases and in reduction of food borne pathogens.

The present trial is conducted to determine the effects of usage of Na-butyrate encapsulated in palm fat on experimentally induced $\mathrm{NE}$ and resident $C$. perfringens enumeration (intestinal colonization). 


\section{Material and Methods}

Na-butyrate:Na-butyrate encapsulated in palm fat (Admix ${ }^{\circledR} 30$ produced by NUTRI-AD International, Belgium) was used in this trial in the following dietary levels in the test groups; starter diet: $1 \mathrm{~kg} / \mathrm{ton}$, grower diet: $0.5 \mathrm{~kg} / \mathrm{ton}$ and finisher diet: $0.25 \mathrm{~kg} / \mathrm{ton}$

\section{Experimental design:}

One day-old male Arbor Acres plus broiler chickens $(n=800)$ were used in this study. Duration of the trial extended from one day of age up to slaughter (35 days). These birds were allotted into 4 equal groups (1-4) consisting of 200 birds each and assigned into 10 equal replicates of 20 birds. All groups ran contemporaneously. Chickens of groups 1 and 3 treated with Admix ${ }^{\circledR} 30$ while groups 2 and 4 fed on a plain ration without treatment.

As immunosuppressed chickens are more likely to develop NE, so that some researchers have used methods to induce immunosuppression. These methods mostly use Infectious Bursal Disease vaccine (IBD); it has resulted in a significant increase in NE lesions (McReynolds et al. 2004). Accordingly; vaccination against infectious bursal disease (IBD) using 228 -E vaccine was given at $14^{\text {th }}$ day of age. At the same day of age; birds of groups 1 and 2 were individually infected by crop gavages with $4 \times 10^{8} \mathrm{CFU} / \mathrm{ml} / \mathrm{bird}$ of $C$. perfringens in phosphate buffered saline (PBS) for 4 successive days after Olkowski et al. (2006), Gholamiandehkordi et al. (2007) and Timbermont et al. (2009). Chickens of groups 3 and 4 were kept without infection. The used strain of $C$. perfringens was type A B2 NET B, isolated from cases of chicken NE.

All experimented birds were vaccinated against different diseases according to the vaccination programs usually adopted in Egyptian chicken broiler farms. Chicken groups 1 and 2 (C. perfringens challenged) were kept in a separate room and those of groups 3 and 4 (non-challenged) were kept in another room. All chickens were floor reared in separate pens and kept in environmentally controlled rooms.

Diets:

Chickens fed ad libitum a mash commercial starter diet (23\% crude protein and $3000 \mathrm{k}$ cal ME/kg diet) during the first 2 weeks of age, commercial grower diet (22\% crude protein and $3150 \mathrm{kcal} \mathrm{ME} / \mathrm{kg}$ diet) from 2-4 weeks of age, and then commercial finisher diet (19\% crude protein and $3200 \mathrm{kcal} \mathrm{ME} / \mathrm{kg}$ diet) from 4-5 weeks of age. Birds had free access to water. No chemotherapy (neither antibiotic, nor anticoccidial drug or coccidiostate) was added during the entire period of the trial.

\section{Measured parameters:}

\section{Intestinal colonization of C. perfringens (Bioassay):}

For intestinal colonization of $C$. perfringens 10 birds of the 4 groups were randomly sacrificed at 14, 21 and 28 days post infection (PI) (1 bird/replicate). Following euthanasia, birds necropsied and $0.2 \mathrm{~g}$ of intestinal contents from each bird were serially diluted in sterile PBS to 1:100, 1:1000, and 1:10000 and $0.1 \mathrm{ml}$ of each dilution and poured on the surface of sheep blood agar plates and tryptose sulfite-cycloserine (TSC) agar (supplemented by D-cycloserine) with egg yolk emulsion. These were overlaid with the same medium but without egg yolk. After anaerobic incubation at $37^{\circ} \mathrm{C}$ for 24 hours; typical C. perfringens colonies (black colonies) on TSC agar or large dome-shaped colonies with a double zone of hemolysis on blood agar plates counted and reported as colony-forming units (CFU) per gram. The colonies picked and confirmed by criteria of Harmon (1984) and Carrido et al. (2004).

II- Lesion scoring of gut:

Necropsied birds at day 21 and 28 examined for gross pathological lesion scoring of the small intestine. The scoring system criteria were the six-point system of Keyburn et al. (2006) modified by Shojadoost et al. (2012) as follows:

$0=$ No gross lesions -

$1=$ Thin or friable walls, or diffuse superficial but removable fibrin

$2=$ Focal necrosis or ulceration, or non-removable fibrin deposit 1 to 5 foci

$3=$ Focal necrosis or ulceration, or non-removable fibrin deposit 6 to 15 foci

$4=$ Focal necrosis or ulceration, or non-removable fibrin deposit 16 or more foci

$5=$ Patches of necrosis 2 to $3 \mathrm{~cm}$ long variable

$6=$ Diffuse necrosis typical of field cases variable, but extensive.

III-Health status and Mortality assay:

During the evaluation; the health status of the birds checked daily. 


\section{Statistical analyses:}

One-way analysis of variance adopted using SAS software general liner models procedure (SAS Institute, 2000). The main factor was Admix 30 supplementation as a mean effect. Mean values assessed for significance using Duncan's multiple range tests. The following model was used for data analysis: $Y_{i j}=\mu+a_{i}+$ $\mathrm{e}_{\mathrm{ij}}$

Where: $Y_{\mathrm{ij}}$ : The $\mathrm{J}^{\text {th }}$ observation of the $\mathrm{i}^{\text {th }}$ dose of Admix 30.

$\mu$ : Overall mean.

$\mathrm{a}_{\mathrm{i}}$ : Effect of dose of Admix $30(\mathrm{I}=1,2)$.

$\mathrm{e}_{\mathrm{ij}}$ : Unexplained error.

Statements of statistical significance are based upon $\mathrm{P} \leq 0.05$.

\section{Results and Discussion}

In the present investigation experimental induction of NE successfully achieved by daily oral inoculation of $4 \times 10^{8} \mathrm{CFU}$ of $C$. perfringens/ bird in PBS for 4 successive days to immunocompromised broiler chickens (using IBDV vaccination with a hot vaccinal strain). Experimentally infected bird groups showed variable degrees of diarrhea, inappetance enteritis and mortalities.

The recorded mortality was lower in Admix 30 treated groups vs. their non-treated ones which could be attributed to its antibacterial effect (Table 1).

The average lesion scoring reached 1.8 and 0.4 in NE infected treated group with Admix 30 (group 1) vs. 2.6 and 0.7 in NE infected non treated group (group 2) at $7^{\text {th }}$ and $14^{\text {th }}$ day post $C$. perfringens challenge respectively indicating the efficacy of Admix 30 in lowering damage associated with NE (Table 2 and Fig.1). Enumeration of GIT resident $C$. perfringens at $14^{\text {th }}$ day of age revealed diverse values; with higher levels found in non treated blank control birds (group 4) as compared with Admix 30 treated birds (group 3). Similar finding was also determined at $28^{\text {th }}$ day of age in the same group. On the other hand; $C$. perfringens enumeration in NE infected group reduced these values at different examined intervals in Admix 30 treated birds (group 1) vs. nontreated NE infected birds (group 2) (Table 3). Aforementioned findings could be attributed to the pH-reducing and antimicrobial effects of Admix 30 as an acidifier; a conclusion which completely accords with that reported by Lückstädt (2003). Obtained bacteriological results might be explained in the view of the report of Dhawale (2005) who mentioned that organic acids in non-dissociated state (non-ionized) are more lipophilic, penetrate the semi-permeable membrane of the bacterial cell wall and enter the cytoplasm. He concluded that the antibacterial effects of organic acids work through: modification of internal $\mathrm{pH}$; inhibition of fundamental metabolic functions; accumulation of toxic anions and disruption of the cellular membrane

Although the most effective method to prevent or to control NE is the use of antimicrobials mixed to feed and water, bacterial resistance to bacitracin, tetracycline, clindamycin, lincomycin and erythromycin has been reported in several countries, such as, Denmark, Switzerland, Norway, Belgium, Jordan and Brazil (Silva et al, 2009, Gharaibeh et al. 2010 and Salvic et al. 2011). In countries that have stopped of using AGP, the problems of diseases associated with $C$. perfringens in broiler chickens have increased (Grave et al.; 2004). Taking in consideration our obtained findings ( $C$. perfringens enumeration, mortality rates and lesion scoring of experimentally induced $\mathrm{NE}$ ); the role of $\mathrm{Na}$ butyrate encapsulated in palm fat (Admix 30) is a powerful environmentally friendly alternative that cannot be denied as a natural control method for NE in poultry enterprises. This argument confirms findings of Awaad et al. (2011) who clearly showed that using acidifiers is considered a novel and effective alternative to antibiotics that could reduce the severity of $C$. perfringens associated with NE in broiler chickens.

Food safety is probably the biggest issue facing poultry production systems today. Preventing contamination of poultry products with food borne pathogens remains a considerable challenge for producers and integrations. Ghadban et al. (1998) and Brynestad (2002) reported on C. perfringens as one of the food borne pathogens responsible for the severe food borne necrotic enteritis in man (enteritis necroticans or pigbel disease) which is fatal specially in young and elderly and its enterotoxin has been shown to be the virulence factor responsible for causing the symptoms of $C$. perfringens type A food poisoning which is the more common in the industrialized world. Eventually; the present investigation proves the effectiveness of $\mathrm{Na}$ butyrate encapsulated in palm fat (as an animal feed acidifier) in reducing enumeration of resident as well as experimentally induced $C$. perfringens and reducing the severity of $\mathrm{NE}$ in broilers which seems to be essential to the higher need for top quality poultry. 
Table 1. Effect of Admix 30 on mortality of $C$. perfringens infected and non-infected broiler chickens.

\begin{tabular}{|c|c|c|c|c|c|c|}
\hline \multirow{2}{*}{$\begin{array}{c}\text { Group } \\
\text { No. }\end{array}$} & \multicolumn{4}{|c|}{ Weekly Mortality Rate (\%) } & \multicolumn{2}{c|}{$\begin{array}{c}\text { Cumulative } \\
\text { Mortality Rate }\end{array}$} \\
\cline { 2 - 7 }$n$ & 1 Week & 2 Weeks & 3 Weeks & 4 Weeks & 5 Weeks & ( $) .88 \pm 1.93$ \\
\hline 1-Admix30+CPI* & $2.22 \pm 1.13$ & $2.59 \pm 0.96$ & $0.00 \pm 0.00$ & $1.48 \pm 0.82$ & $2.59 \pm 1.24$ & $12.58 \pm 3.27$ \\
\hline 2-Control+CPI & $2.59 \pm 0.79$ & $1.48 \pm 0.82$ & $1.11 \pm 1.11$ & $3.33 \pm 1.51$ & $4.07 \pm 1.78$ & $7.40 \pm 1.23$ \\
\hline 3-Admix30 & $2.96 \pm 0.49$ & $1.48 \pm 0.60$ & $0.37 \pm 0.37$ & $1.48 \pm 0.82$ & $1.11 \pm 0.57$ & $10.73 \pm 1.60$ \\
\hline 4-Blank Control & $2.22 \pm 0.82$ & $1.85 \pm 0.83$ & $1.11 \pm 0.57$ & $1.85 \pm 0.99$ & $3.70 \pm 1.10$ & 0.3650 \\
\hline Probability & 0.9104 & 0.7441 & 0.5410 & 0.5727 & 0.3493 & \\
\hline
\end{tabular}

$* \mathrm{CPI}=C$. perfringens infection

Table2. Results of lesion score post NE induction

\begin{tabular}{|c|c|c|c|c|c|}
\hline \multicolumn{6}{|c|}{21 day-old chickens (7 days PI) } \\
\hline $\begin{array}{c}\text { Groups } \\
\text { No. }\end{array}$ & $\begin{array}{c}\text { Lesion } \\
\text { score }^{* *} \text { of } \mathrm{NE}\end{array}$ & No. of birds/score & $\begin{array}{c}\text { No. of } \\
\text { examined } \\
\text { birds/group }\end{array}$ & $\begin{array}{c}\text { Total lesion } \\
\text { score / group }\end{array}$ & $\begin{array}{c}\text { Average lesion } \\
\text { score }\end{array}$ \\
\hline \multirow{3}{*}{ 1-Admix30 +CPI* } & 1 & 5 & \multirow{3}{*}{10} & \multirow{3}{*}{18} & \multirow{3}{*}{1.8} \\
\hline & 2 & 2 & & & \\
\hline & 3 & 3 & & & \\
\hline \multirow[t]{2}{*}{ 2-Control + CPI } & 2 & 4 & \multirow[t]{2}{*}{10} & \multirow[t]{2}{*}{26} & \multirow[t]{2}{*}{2.6} \\
\hline & 3 & 6 & & & \\
\hline 3-Admix30 & 0 & 10 & 10 & 0 & 0 \\
\hline 4-Blank Control & 0 & 10 & 10 & 0 & 0 \\
\hline \multicolumn{6}{|c|}{28 day old chickens (14 days PI) } \\
\hline \multirow[b]{2}{*}{ 1-Admix30 +CPI* } & 0 & 6 & \multirow[t]{2}{*}{10} & \multirow[t]{2}{*}{4} & \multirow[t]{2}{*}{0.4} \\
\hline & 1 & 4 & & & \\
\hline \multirow{3}{*}{ 2-Control + CPI } & 0 & 5 & \multirow{3}{*}{10} & \multirow{3}{*}{7} & \multirow{3}{*}{0.7} \\
\hline & 1 & 3 & & & \\
\hline & 2 & 2 & & & \\
\hline 3-Admix30 & 0 & 10 & 10 & 0 & 0 \\
\hline 4-Blank Control & 0 & 10 & 10 & 0 & 0 \\
\hline
\end{tabular}

$* \mathrm{CPI}=C$. perfringens infection

**Lesion score after Keyburn et al. (2006) modified by Shojadoost et al. (2012).

Table 3. Means of enumeration of resident and experimentally induced $C$. perfringens $\left(10^{3} \mathrm{CFU} / \mathrm{g}\right)$.

\begin{tabular}{|l|c|c|c|}
\hline \multirow{2}{*}{ Group No. } & \multicolumn{3}{|c|}{ Age of broiler chickens } \\
\cline { 2 - 4 } & 14 days & 21 days & $2.353 \pm 1.030$ \\
\hline 1-Admix30 + CPI* & $0.042 \pm 0.020^{\mathrm{b}} * *$ & $11.920 \pm 8.727^{\mathrm{b}}$ & $55.630 \pm 19.545$ \\
\hline 2-Control + CPI & $0.260 \pm 0.094^{\mathrm{ab}}$ & $353.200 \pm 94.154^{\mathrm{a}}$ & $0.430 \pm 0.398$ \\
\hline 3-Admix30 & $31 \pm 0.019^{\mathrm{b}}$ & $0.180 \pm 0.0772^{\mathrm{b}}$ & $69.200 \pm 59.312$ \\
\hline 4-Blank Control & $300 \pm 0.133^{\mathrm{a}}$ & $0.080 \pm 0.0335^{\mathrm{b}}$ & 0.2878 \\
\hline Probability & 0.0462 & 0.0001 & \\
\hline
\end{tabular}

$* \mathrm{CPI}=C$. perfringens infection

** Means with different, superscripts, within age, are significantly different $(\mathrm{P} \leq 0.05)$.

\section{References}

[1]. Awaad M. H. H., A. M. Atta, M. Elmenawey, B. Shalaby, G. A. Abdelaleem, K. Madian, K. Ahmed, D. Marzin, G. Benzoni and D.K. Iskander (2011). Effect of Acidifiers on Gastrointestinal Tract Integrity, Zootechnical Performance and Colonization of Clostridium Perfringens and Aerobic Bacteria in Broiler Chickens. Journal of American Science, 7(4):618-628]. (ISSN: 15451003). http://www.americanscience.org.

[2]. Barnes, H.J. (1997). Clostridial diseases. In: Diseases of Poultry. CALNEK, B.W., BARNES, H.J., BEARD, C.W., MCDOUGALD, L.R. \& SAIF, Y.M. 10th.Ed.Iowa State University Press Ames,Iowa USA. pp 255 - 264

[3]. Brynestad, S. (2002). Clostridium perfringens and food borne infections. International Journal of food microbiology, 74 (3):195202.

[4]. Carrido, M.N., Skjerheim, M., Oppegaard, H. and Sqrum, H. (2004). Acidified litter benefits the intestinal flora balance of broiler chickens. Applied and Environmental Microbiology, 70 (9): 52085215.

[5]. Collier C., Hofacre C., Payne A., Anderson D., Kaiser P., Mackie R. and Gaskins H. (2008). Coccidia-induced mucogenesis promotes the onset of necrotic enteritis by supporting Clostridium perfringens growth. Vet Immunol. Immunopathol. 122(1-2), 104115 .

[6]. Cooper KK, Songer JG (2010). Virulence of Clostridium perfringens in an experimental model of poultry necrotic enteritis. Vet Microbiol, 142:323-328.

[7]. Dhawale, A. (2005). Better egg quality with a gut acidifier. Poultry International, Vol. 44, April 2005, Watt Publishing Co., U.S.A. enteritis. Poult Sci 2004, 83:1948-1952.

[8]. Ghadban, G., Kabakchiev, M. and Angelov, A. (1998). Efficacy of different methods of probiotic treatment in preventing infection of broiler chicks. Proceedings of 10th European Poultry Conference. June 21-26, Jerusalem, Israel, Vol. II, 305-310.

[9]. Gharaibeh S., Al Rifai R. and Al-Majali A. (2010). Molecular typing and antimicrobial susceptibility of Clostridium perfringens from broiler chickens. Anaerobe. 16:586-589.

[10]. Gholamiandehkordi AR, Timbermont L, Lanckriet A, Van Den Broeck W, Pedersen K, Dewulf J, Pasmans F, Haeesbrouck F, Ducatelle R, Van Immerseel F (2007). Quantification of gut lesions in a subclinical necrotic enteritis model. Avian Pathol.2007;36:375-382. 
[11]. Grave K., Kaldhusdal M., Kruse H., Fevang Harr L. and Flatlandsmo K. (2004). What has happened in norway after the ban of avoparcin? Consumption of antimicrobials by poultry.Prev. Vet. Med., 62(1), 59-72.

[12]. Harmon, S.M. (1984). Clostridium perfringens: enumeration and identification. In FDA bacteriological analytical manual. Association of official analytical chemists. Arlington, VA: 1701-1710.

[13]. Kaldhusdal, M. and A.L. Lovland. (2000). The economical impact of Clostridium perfringens is greater than anticipated. World Poultry 16, No. 8:50-51.

[14]. Keyburn AL, Sheedy SA, Ford ME, Williamson MM, Awad MM, Rood JI, Moore RJ (2006). Alpha toxin of Clostridium perfringens is not an essential virulence factor in necrotic enteritis in chickens. Infect Immun. 74:6496-6500.

[15]. Kondo F. (1988). In vitro lecithinase activity and sensitivity to 22 antimicrobial agents of Clostridium perfringens isolated from necrotic enteritis of broiler chickens. Res Vet Sci, 45:337-340.

[16]. Llanco L.A., Viviane Nakano, Ferreira A.J.P. and Avila-Campos M.J. (2012). Toxinotyping and antimicrobial susceptibility of Clostridium perfringens isolated from broiler chickens with necrotic enteritis. International Journal of Microbiology Research

ISSN: $\quad 0975-5276 \quad \& \quad$ e-ISSN: 0975-9174, volume 4, issue 7, pp.-290-294 .Available online at http://www.bioinfo.in/contents.php?id=27

[17]. Lückstädt, C. (2003). Biotronic-solutions for modern livestock production. Biomin Newsletter, 3: 1-4.

[18]. McReynolds L, Byrd JA, Anderson RC, Moore RW, Edrington TS, Genovese KJ, Poole TL, Kubena LF, Nisbet DJ (2004). Evaluation of Immunosuppressant and dietary mechanisms in an experimental disease model for necrotic enteritis. Poultry Sci. 83:1948-1952.

[19]. Olkowski AA, Wojnarowicz C, Chirino-Trejo M, Drew MD (2006). Responses of broiler chickens orally challenged with Clostridium perfringens isolated from field cases of necrotic enteritis. Res Vet Sci, 81:99-108

[20]. Salvic D., Boerlin P., Fabri M., Klotins K., Zoethout J., Weir P. and Bateman D. (2011). Antimicrobial susceptibility of Clostridium perfringens isolates of bovine, chicken, porcine, and turkey origin from Ontario. Can. J. Vet. Res., 75(2), 89-97.

[21]. SAS $\AA^{\circledR}$ (2000). User's Guide, Release 8th ed. (Cary, NC, SAS Institute).

[22]. Sengupta N., Alam S., Kumar R. and Singh L. (2011). Diversity and antibiotic susceptibility pattern of cultivable anaerobic bacteria from soil and sewage samples of India. Infec Genet Evol. 11(1), 64-77.

[23]. Shojadoost B., Andrew R Vince and John F Prescott. (2012). The successful experimental induction of necrotic enteritis in chickens by Clostridium perfringens a critical review. Veterinary Research 43:74-86. http://www.veterinaryresearch.org/content/43/1/74.

[24]. Silva, R. O. S., Salvarani F. M., Assis R. A., Martins N. R. S., Pires P. S. and Lobato F. C. F. (2009). Antimicrobial susceptibility of Clostridium perfringens strains isolated from broiler chickensBraz. J. Microbiol. 40(2), 262-264.

[25]. Songer J.G. (1996). Clostridial enteric diseases of domestic animals. Clin Microbiol Rev, 9:216-234.

[26]. Timbermont L, Lanckriet A, Gholamiandehkordi AR, Pasmans F, Martel A, Haesebrouck F, Ducatelle R, Van Immerseel F (2009). Origin of Clostridium perfringens isolates determines the ability to induce necrotic enteritis in broilers. Comp Immunol Microbiol Infect Dis, 32:503-512

[27]. Van der Sluis W (2000). Clostridial enteritis is an often underestimated problem. World Poultry, 16:42-43.

[28]. Van Immerseel F, De Buck J, Pasmans F, Huyghebaert G, Haesebrouck F, Ducatelle R (2004). Clostridium perfringens in poultry: an emerging threat for animal and public health. Avian Pathol. 33:537-549.

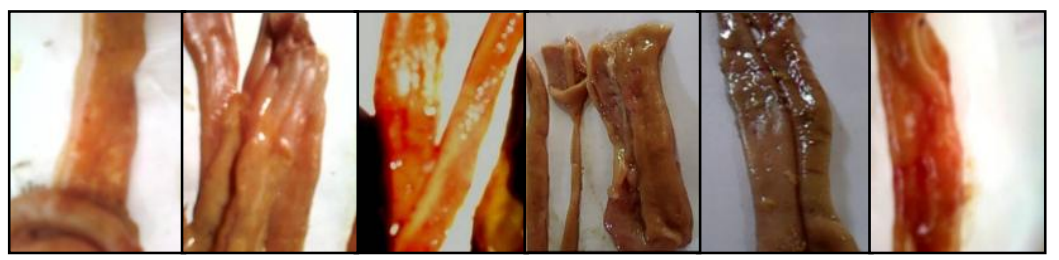

Fig.1. Different intestinal lesions recorded in experimentally induced NE in broiler chickens. 